\title{
Corrigendum: Simple, standardized incorporation of genetic risk into non-genetic risk prediction tools for complex traits: coronary heart disease as an example
}

\author{
Benjamin A. Goldstein ${ }^{1 *}$, Joshua W. Knowles ${ }^{2}$, Elias Salfati ${ }^{2}$, John P. A. loannidis ${ }^{3}$ and \\ Themistocles L. Assimes ${ }^{2}$ \\ ${ }^{1}$ Department of Biostatistics and Bioinformatics, Center for Predictive Medicine, Duke Clinical Research Institute, Duke \\ University, Durham, NC, USA, ${ }^{2}$ Division of Cardiovascular Medicine, Stanford University, Stanford, CA, USA, ${ }^{3}$ Department of \\ Medicine, Stanford Prevention Research Center, Stanford University, Stanford, CA, USA
}

Keywords: risk prediction, genetic risk score (GRS), electronic health records, cardiovascular diseases, coronary disease, biomarkers

\section{OPEN ACCESS}

Edited and reviewed by:

Helena Kuivaniemi,

Geisinger Health System, USA

*Correspondence:

Benjamin A. Goldstein

ben.goldstein@duke.edu

Specialty section:

This article was submitted to Applied Genetic Epidemiology,

a section of the journal

Frontiers in Genetics

Received: 27 May 2015

Accepted: 16 June 2015

Published: 07 July 2015

Citation:

Goldstein BA, Knowles JW, Salfati E, Ioannidis JPA and Assimes TL (2015)

Corrigendum: Simple, standardized

incorporation of genetic risk into

non-genetic risk prediction tools for complex traits: coronary heart disease as an example. Front. Genet. 6:231.

doi: 10.3389/fgene.2015.00231

\section{A corrigendum on}

Simple, standardized incorporation of genetic risk into non-genetic risk prediction tools for complex traits: coronary heart disease as an example

by Goldstein, B. A., Knowles, J. W., Salfati, E., Ioannidis, J. P. A. and Assimes TL (2014). Front. Genet. 5:254. doi: 10.3389/fgene.2014.00254

The original Figure 2 did not display the full sample risk report as described in the paper. Here we illustrate how one can convey personalized genetic risk to a patient and how the inclusion of the Genetic Risk Score changes the clinical interpretation of the individual's risk.

\section{Funding}

BG is supported by an NIH career development award K25DK097279. JK is supported by an American Heart Association, National Fellow to Faculty Award, 10FTF3360005. TA is supported by an NIH career development award K23DK088942.

Conflict of Interest Statement: The authors declare that the research was conducted in the absence of any commercial or financial relationships that could be construed as a potential conflict of interest.

Copyright $\odot 2015$ Goldstein, Knowles, Salfati, Ioannidis and Assimes. This is an open-access article distributed under the terms of the Creative Commons Attribution License (CC BY). The use, distribution or reproduction in other forums is permitted, provided the original author(s) or licensor are credited and that the original publication in this journal is cited, in accordance with accepted academic practice. No use, distribution or reproduction is permitted which does not comply with these terms. 


\section{YOUR RISK SCORE}

Based on the traditional Framingham risk score, your risk of coronary heart disease over the next 10 years is approximately $5.5 \%$.

We tested for a total of 90 possible risks variants or alleles. Out of these 90, you carry 49 variants that are associated with higher risk. Your genetic profile puts you in the 89 percentile for risk. This means $89 \%$ of the general population have a genetic risk score more favorable than you and $11 \%$ have a genetic risk score less favorable than you.

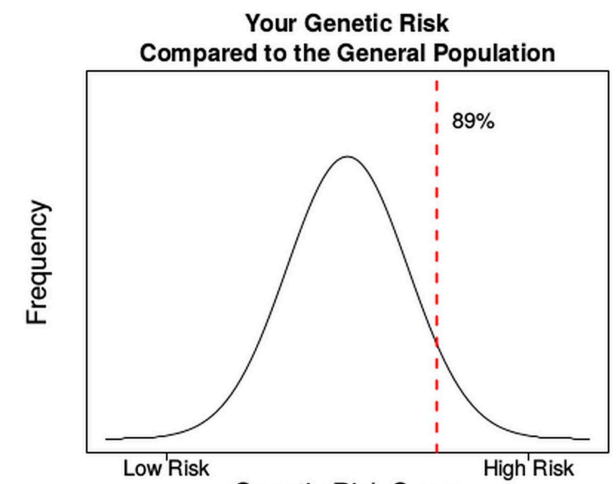

Based on the traditional Framingham risk score plus the genetic risk score, your risk of coronary heart disease over the next 10 years is approximately $7.6 \%$.

Your 10 year risk of coronary heart disease risk is $\geq 7.5 \%$ when considering your genetic risk. This information may be discussed with your physician in terms of what would be recommended as most appropriate management given your estimated risk. 